\title{
Educação, trabalho e tecnologias: a reflexão filosófica no ensino médio técnico
} Education, work and technologies: a philosophical reflection on technical high school

\author{
Daniel Salésio Vandresen ${ }^{\mathbf{1}}$ \\ daniel.vandresen@ifpr.edu.br
}

\section{Resumo}

Este trabalho tem por objetivo refletir sobre o papel da filosofia para a formação do sujeito autônomo na educação tecnológica. O estudo tem como contexto de análise a reflexão sobre a tríplice relação entre a educação, o trabalho e as tecnologias, tendo como questão norteadora a problematização do ensino técnico entre a formação de uma subjetividade autônoma ou apenas para adaptação às necessidades mercadológicas. O texto apresenta ainda a análise do conceito de trabalho como princípio educativo como requisito para a compreensão histórica do conhecimento científico e tecnológico. Por fim, relata-se a experiência de pesquisa sobre a utilização do blog na educação, atividade realizada com alunos do ensino médio técnico do IFPR/Campus Assis Chateaubriand.

Palavras-chave: Filosofia; Trabalho; Educação; Subjetividade; Tecnologias.

\section{Abstract}

This work aims to reflect on the role of philosophy for the formation of the autonomous subject in technological education. The study is to analyze the context of the debate on the threefold relationship between education, work and technologies, having as guiding question the questioning of Technical Education between the formation of an autonomous subjectivity and just adapting to the market needs. The text also presents the analysis of the concept of work as an educational principle as a requirement for the historical understanding of scientific and technological knowledge. Finally, we report the research experience on the use of the blog in the education activity conducted with high school students Technician IFPR/Campus Assis Chateaubriand.

Keywords: Philosophy; Work; Education; Subjectivity; Technologies.

\footnotetext{
1 Mestre em Filosofia pela Unioeste/Toledo-PR. Professor do Instituto Federal do Paraná IFPR/Campus Assis Chateaubriand. Pesquisador do Grupo de Pesquisa: Filosofia, Ciência e Tecnologias.
} 


\section{Introdução}

O presente estudo visa a discutir a formação de uma subjetividade emancipatória na educação tecnológica do Instituto Federal do Paraná/Câmpus Assis Chateaubriand. O contexto da análise diz respeito à complexidade da formação de nível médio (última fase da educação básica), em sua relação com o mundo do trabalho e a sociedade tecnológica. Para realizar esse empreendimento teórico, busca-se a fundamentação na reflexão do conceito de trabalho educativo e no papel da disciplina de filosofia, para compreensão da relação entre a educação, o trabalho e as tecnologias.

Este trabalho está dividido em três momentos: primeiro, abordam-se os fundamentos do trabalho como princípio educativo; em seguida, apresenta-se a legislação educacional, e, como nela, se reorganiza o ensino médio, através desse princípio; depois, resgatam-se alguns teóricos que ajudam a problematizar a tríplice relação educação, trabalho e tecnologias, como também, o papel da filosofia nesse processo; por fim, apresentam-se os resultados de uma pesquisa realizada com alunos do ensino médio.

\section{O conceito de trabalho como princípio educativo}

O trabalho como princípio educativo está muito presente nos debates da educação brasileira, tanto na legislação (próximo tópico), como também na base teórica de reflexão da educação de pensadores como Dermeval Saviani, Gaudêncio Frigotto e Álvaro Vieira Pinto. Contudo, essa ideia remete ao pensamento de Antonio Gramsci (2001) em sua reflexão sobre a escola unitária. Para o autor, o princípio educativo da educação é o trabalho, porque esse não pode se realizar sem o conhecimento de sua produção.

O conceito e o fato do trabalho (da atividade teórico-prática) é o princípio educativo imanente à escola primária, já que a ordem social e estatal (direitos e deveres) é introduzida e identificada na ordem natural pelo trabalho. O conceito do equilíbrio entre ordem social e ordem natural com base no trabalho, na atividade teórico-prática do homem, cria os primeiros elementos de uma intuição do mundo liberta de toda magia ou bruxaria e fornece o ponto de partida para o posterior desenvolvimento de uma concepção histórica, dialética, do mundo, para a compreensão do movimento e do devir. (GRAMSCI, 2001, p. 43) 
Nessa citação, Gramsci mostra que o trabalho, como atividade teórica (conceito) e prática (fato), permite ao processo educativo uma formação históricodialética do mundo. Segundo Frigotto, Ciavatta e Ramos (2013), esse duplo sentido do trabalho também está expresso no pensamento de Lukács, o qual aborda o trabalho pela dimensão ontológica e histórica. A dimensão ontológica do trabalho revela que, por meio dele, o ser humano se humaniza, cria, produz conhecimento e se aperfeiçoa. Pela dimensão histórica, o trabalho permite compreender sua utilização como força produtiva e sua consequência de trabalho explorado. Para Saviani (2007), em uma concepção ontológico-histórica do vínculo entre educação e trabalho, o homem se torna homem, porque trabalha e educa.

Os autores Frigotto, Ciavatta e Ramos (2013) alertam ainda que, na relação educação e trabalho, é preciso não ser inocente e reconhecer que essa relação é parte da luta hegemônica entre capital e trabalho. É preciso admitir que o trabalho não é necessariamente educativo. Então, como entender essa relação? Para esses autores: "o trabalho, no sentido ontológico, é princípio e organiza a base unitária do ensino médio" (2013, p. 13). Assumir essa postura significa também assumir o trabalho como princípio ético-político, ou seja, uma educação emancipatória, que reconhece a dimensão criativa do trabalho na produção da existência humana e social.

Segundo Ramos (2003), é importante notar que, historicamente, o ensino médio esteve predominantemente centrado na formação para o mercado de trabalho. Isso significa que é preciso deslocar o foco de seus objetivos para a pessoa humana. Ainda afirma que a finalidade do ensino médio deve ser o sujeito e o conhecimento, ou seja, garantir o direito ao conhecimento historicamente construído em uma base unitária, em que o sujeito tenha uma formação que sintetize humanismo e tecnologia. Assumir o trabalho como princípio educativo implica em defender um projeto unitário de educação que supere a dualidade histórica entre a formação básica e a formação profissional.

\section{A legislação educacional e a relação educação, trabalho e tecnologias}

Ao tratar sobre o tema da legislação educacional, começamos pela Lei $n^{\circ}$. 9.394 (Lei de Diretrizes e Bases da Educação Nacional - Ldben), pois é um 
documento que retrata uma conquista na democratização da educação brasileira e o caminho mais apropriado para tematizar o direito à educação. No que diz respeito ao ensino médio, a Ldben define, em seu Art. 35, como finalidade, a preparação para a continuidade dos estudos, a preparação básica para o trabalho e o exercício da cidadania, a formação humana e o pensamento crítico, além da compreensão dos fundamentos científico-tecnológicos dos processos produtivos.

A Ldben, ainda que timidamente, institucionaliza o ensino médio integrado à educação profissional, uma ruptura com a dualidade histórica que separou os estudos preparatórios para a educação superior da formação profissional. Em relação à educação profissional, a Lei ㄲo. 11.741 (2008) altera os dispositivos da Ldben e institucionaliza e integra as ações da educação profissional técnica de nível médio.

A Lei ํo. 11.741 revaloriza a possibilidade do ensino médio integrado com a educação profissional técnica. Uma de suas principais orientações teóricas é a integração entre trabalho, ciência e tecnologia. Conforme o Art. 39: "A educação profissional e tecnológica, no cumprimento dos objetivos da educação nacional, integra-se aos diferentes níveis e modalidades de educação e às dimensões do trabalho, da ciência e da tecnologia".

Em 2000, foram elaborados os Parâmetros Curriculares Nacionais (PCNs) do Ensino Médio, com base na Resolução CEB no 3, de 26 de junho de 1998 (que institui as Diretrizes Curriculares Nacionais para o Ensino Médio). Os PCNs têm por objetivo pensar as diretrizes para um "novo ensino médio", em face do diagnóstico das transformações da sociedade contemporânea. Para os PCNs (2000, p. 4) "[...] as novas tecnologias $e$ as mudanças na produção de bens, serviços e conhecimentos exigem que a escola possibilite aos alunos integrarem-se ao mundo contemporâneo nas dimensões fundamentais da cidadania e do trabalho".

Segundo os PCNs (2000, p. 5) dois fatores determinam a urgência de pensar as diretrizes para o "novo ensino médio": o fator econômico, que é marcado pela ruptura tecnológica característica da chamada terceira revolução técnico-industrial, e uma nova compreensão teórica sobre o papel da escola, estimulada pela incorporação das novas tecnologias. 
Segundo a Resolução CEB ํo 3, Art. 10, a base nacional comum dos currículos do ensino médio será organizada em áreas de conhecimento, a saber: 1 Linguagens, Códigos e suas Tecnologias, II - Ciências da Natureza, Matemática e suas Tecnologias e III - Ciências Humanas e suas Tecnologias.

Os PCNs (2000) justificam essa organização:

A estruturação por área de conhecimento justifica-se por assegurar uma educação de base científica e tecnológica, na qual conceito, aplicação e solução de problemas concretos são combinados com uma revisão dos componentes socioculturais orientados por uma visão epistemológica que concilie humanismo e tecnologia ou humanismo numa sociedade tecnológica. (p.19)

A defesa da organização por áreas de conhecimento se fundamenta na ideia da articulação entre tecnologia e epistemologia. Daí a importância da filosofia (descrita no próximo tópico).

Especificamente para o Ensino Médio, em 2011, foi elaborado o Parecer CNE/CEB no 5/2011 (Diretrizes Curriculares Nacionais para o Ensino Médio) e, em 2012, a Resolução oํ 2, de 30 de Janeiro de 2012 (Define Diretrizes Curriculares Nacionais para o Ensino Médio).

Esses documentos visam à construção de um ensino médio a partir de quatro dimensões da condição humana: trabalho, ciência, tecnologia e cultura, as quais procuram definir. Também pretendem estabelecer o trabalho como princípio educativo e a pesquisa como princípio pedagógico.

A Resolução no 2/2012, no Art. 5, define esses quatro elementos:

$\S 1^{\circ} \mathrm{O}$ trabalho é conceituado na sua perspectiva ontológica de transformação da natureza, como realização inerente ao ser humano e como mediação no processo de produção da sua existência.

$\S 2^{\circ}$ A ciência é conceituada como o conjunto de conhecimentos sistematizados, produzidos socialmente ao longo da história, na busca da compreensão e transformação da natureza e da sociedade.

$\S 3^{\circ} \mathrm{A}$ tecnologia é conceituada como a transformação da ciência em força produtiva ou mediação do conhecimento científico e a produção, marcada, desde sua origem, pelas relações sociais que a levaram a ser produzida.

$\S 4^{\circ}$ A cultura é conceituada como o processo de produção de expressões materiais, símbolos, representações e significados que correspondem a valores éticos, políticos e estéticos que orientam as normas de conduta de uma sociedade.

O Parecer CNE/CEB no 5/2011 (p. 19s), base para a Resolução 02/2012, já havia estabelecido essas definições e, com mais clareza, na interação entre os elementos. Esse parecer, partindo da conceituação ontológica e histórica do 
trabalho, compreende o mesmo como ponto de partida para a produção científica ("a ciência é o resultado de um processo empreendido pela humanidade, em um movimento permanente de construção de novos conhecimentos, na busca da compreensão e transformação dos fenômenos naturais e sociais"), do desenvolvimento da tecnologia ("transformação da ciência em força produtiva, que visa à satisfação das necessidades da humanidade") e da produção da cultura ("a produção de expressões materiais, símbolos, representações e significados que correspondem a valores éticos e estéticos que orientam as normas de conduta de uma sociedade"). Desse modo, "evidencia-se a unicidade entre as dimensões científico-tecnológico-cultural, a partir da compreensão do trabalho em seu sentido ontológico" (Parecer CNE/CEB o 5/2011, p. 20). E completa, porque esses elementos não se produzem independente da sociedade, eles devem ser base da proposta e do desenvolvimento curricular no ensino médio.

Devido a essa centralidade do conceito de trabalho, esses documentos definem o trabalho como princípio educativo. O Parecer CNE/CEB no 5/2011 (p. 21) elenca dois motivos para defender tal ideia. Primeiro, porque considerar o trabalho como princípio educativo equivale a dizer que o ser humano é sujeito de sua história, que é produtor de sua realidade, dela se apropria e pode transformá-la. Segundo, proporciona a compreensão do processo histórico de produção científica e tecnológica, como conhecimentos desenvolvidos e apropriados socialmente para a transformação da existência humana, ideia também presente no item II do Art. 13 da Resolução no 2/2012.

Em relação à educação profissional, em 2012, foi elaborado o Parecer CNE/CEB no 11/2012 (que estabelece as Diretrizes Curriculares Nacionais para a Educação Técnico de Nível Médio) e a Resolução no 6, de 20 de Setembro de 2012 (Define Diretrizes Curriculares Nacionais para a Educação Profissional Técnica de Nível Médio). Esses documentos pretendem reger novas diretrizes para o ensino médio, em meio as novas relações de trabalho nesta sociedade tecnológica.

Para o Parecer CNE/CEB oํ 11/2012, o mundo do trabalho funciona como referência para a educação profissional, pois orienta o direcionamento formativo, o qual precisa fornecer, além do domínio operacional de um determinado fazer, também precisa aliar "[...] a compreensão global do processo produtivo, com a 
apreensão do saber tecnológico, a valorização da cultura do trabalho e a mobilização dos valores necessários à tomada de decisões no mundo do trabalho" (CNE/CEB no 11/2012, p. 8).

Já a Resolução no 6/2012 caminha sob os mesmos pressupostos da Resolução 02/2012, pois assume o trabalho como princípio educativo em sua interação com a ciência, a tecnologia e a cultura. E acrescenta ainda elementos histórico-sociológicos, que os currículos dos cursos de Educação Profissional Técnica de Nível Médio devem proporcionar aos estudantes, como:

I - diálogo com diversos campos do trabalho, da ciência, da tecnologia e da cultura como referências fundamentais de sua formação;

II - elementos para compreender e discutir as relações sociais de produção e de trabalho, bem como as especificidades históricas nas sociedades contemporâneas;

III - recursos para exercer sua profissão com competência, idoneidade intelectual e tecnológica, autonomia e responsabilidade, orientados por princípios éticos, estéticos e políticos, bem como compromissos com a construção de uma sociedade democrática (Art. 14 da Resolução nº 6/2012).

Para o Parecer CNE/CEB no 11/2012 (p. 8), a educação profissional não é identificada como simples instrumento de política assistencialista ou apenas um ajustamento às demandas do mercado de trabalho, mas ela permite ser uma estratégia para que os cidadãos tenham efetivo acesso às conquistas científicas e tecnológicas da sociedade.

\section{A filosofia e a relação educação, trabalho e tecnologias}

Desde a leitura marxista, o trabalho passou a ser a categoria que utilizamos para nos situarmos no mundo. Segundo Frigotto, Ciavatta e Ramos (2013), Karl Marx interpreta o trabalho pela dimensão ontológica, onde o compreende como construção do humano, ou seja, o homem é o que é pelo trabalho criativo e transformador que realiza. Por outro lado, sua crítica histórica ao trabalho alienante da sociedade industrial entende que o trabalhador se desumaniza, pois, através de atividades repetitivas e delimitadas, o operário perde o vínculo com a identidade do trabalho criativo.

A dimensão do trabalho invade o âmbito da educação em diferentes aspectos, por exemplo, na legislação educacional, exerce seu poder, ao garantir leis que a 
direcionam para o mundo do trabalho; já nas concepções teóricas, sua influência aparece na concepção pedagógica do trabalho como princípio educativo.

Segundo Demerval Saviani (2013), até a década de 1960, predominou a tendência de compreender a educação pelo seu caráter improdutivo, como uma atividade caracterizada como não trabalho, mas, a partir da teoria do Capital Humano, a educação passou a ser decisiva para o desenvolvimento econômico, pois dela depende a formação do homo oeconomicus. Essa ideia também é apresentada por Foucault (2008), na obra Nascimento da biopolítica, na qual defende que a partir da Teoria do Capital Humano da ótica neoliberal, o trabalho passou a ser analisado a partir das estratégias de conduta de quem trabalha. $O$ trabalhador deixa de ser um objeto no processo do capital e passa a ser sujeito. Nesse panorama neoliberal, o trabalho aparece como retorno ao homo oeconomicus, mas não mais como homem parceiro da troca na concepção clássica e, sim, como um empresário, um empresário de si mesmo. "homo oeconomicus empresário de si mesmo, sendo ele próprio seu capital, sendo para si mesmo seu produtor, sendo para si mesmo a fonte de [sua] renda" (FOUCAULT, 2008, p. 311). Se, na economia clássica, o indivíduo era explorado pela sua força de trabalho, agora, na concepção neoliberal, o indivíduo vale enquanto seu capital humano é útil para os interesses do mercado. A constituição de um capital humano funciona, na racionalidade neoliberal, como exercício do biopoder (poder sobre a vida). Agir sobre a população, com o objetivo de estimular e garantir que haja capital humano, é a meta da biopolítica neoliberal.

Segundo Gaudêncio Frigotto, Ciavatta e Ramos (2013), não é inocente a direção que assume a relação trabalho e educação no contexto da luta hegemônica entre capital e trabalho. Se, na sociedade industrial, o trabalho era repetitivo, vigiado e mal remunerado, agora, através da ideologia do capitalismo flexível, intensifica-se a exploração por meio da pedagogia das competências, na qual o trabalhador tem que aprender a aprender. Essa ideologia se propaga pela construção de subjetividades, em que o problema depende de cada um e não apenas das relações de poder que compõem a estrutura social.

A passagem para a formação flexível do modelo do toyotismo provocou alterações no trabalho como formação fechada do modelo fordista-taylorista. $\mathrm{Na}$ 
educação, esse reflexo é visível na concepção de educação permanente. Gilles Deleuze (1992), no texto Post-Scriptum sobre as sociedades de controle, relaciona a educação permanente com o que chama de "sociedade de controle". Para o autor, a educação em uma sociedade de controle aparece sob o modelo da empresa, ou seja, nessa realidade, cria-se um ambiente de competição, tendo como princípio o salário por mérito e a ênfase na formação permanente. $O$ autor aponta que, na sociedade disciplinar, era preciso sempre recomeçar, fosse na escola, na fábrica etc.; já na sociedade de controle, nunca se termina nada. No texto a seguir, Deleuze (1992) descreve o que marca a escola nessa sociedade de controle:

No regime das escolas: as formas de controle contínuo, avaliação contínua, e a ação da formação permanente sobre a escola, o abandono correspondente de qualquer pesquisa na Universidade, a introdução da "empresa" em todos os níveis de escolaridade. (p. 226)

Nesse sentido, a ideia de formação permanente/continuada, além de constituir, na sociedade de controle, uma ferramenta capaz de instigar o indivíduo a estar sempre investindo em seu capital humano, também funciona como um poderoso elemento de construção de subjetividade, ou seja, um instrumento político para direcionar as condutas individuais e coletivas sob o modelo das competências e da criatividade. Para Aranha (1996, p. 244), a educação permanente é, ao mesmo tempo, uma exigência dos novos tempos e também uma condição de manter as pessoas ocupadas. Então, seria ilusório pensar que, por meio dela, haja transformação social, e que, ao contrário, sua prática mantenha os indivíduos ocupados consigo e, por consequência, fechados aos problemas éticos e políticos?

No atual cenário de adaptação à economia informacional, a educação tecnológica tem exigido a ampliação da necessidade de formação permanente. Para buscar as competências requeridas pelo capital humano, a educação se torna um investimento, alvo não só do Estado e escolas privadas, mas também de empresas e do próprio trabalhador individualmente.

Por um lado, teóricos como Manuel Castells e Gustavo Cardoso (2005, p. 19s) defendem que essa sociedade tecnológica, a qual denominam como "sociedade em rede", caracterizada por um sistema de produção baseado na flexibilidade, na autonomia e na criatividade, tem capacidades de performance 
superiores em relação aos anteriores sistemas tecnológicos. Afirmam ainda que: "Sabemos, pelos estudos em diferentes sociedades, que a maior parte das vezes os utilizadores de Internet são mais sociáveis, têm mais amigos e contatos e são social e politicamente mais ativos do que os não utilizadores" (CASTELLS; CARDOSO, 2006, p. 23).

Por outro lado, segundo Moacir Viegas (2010, p. 173s), no modelo tayloristafordista, o cotidiano da produção se constitui em um ambiente de pura alienação; já no novo paradigma da economia informacional, os trabalhadores têm maiores condições de expressar sua subjetividade. $\mathrm{E}$ o autor questiona: teria essa condição maior possibilidade de emancipação? Ele afirma que os teóricos da teoria crítica ${ }^{2}$ já mostraram sua visão cética da possibilidade de emancipação da tecnologia. Assim expressa um dos teóricos:

Parece que enquanto o conhecimento técnico expande o horizonte da atividade e do pensamento humanos, a autonomia do homem enquanto indivíduo, a sua capacidade de opor resistência ao crescente mecanismo de manipulação de massas, o seu poder de imaginação e o seu juízo independente sofreram aparentemente uma redução. (HORKHEIMER, 2002, p. 26)

Diante do paradoxo dos autores expostos, uma questão surge: nessa sociedade tecnológica, na qual os indivíduos têm maiores espaços para expressarem suas subjetividades, também estaríamos formando trabalhadores com maiores condições de emancipação social? Precisamos investigar se a formação que a nossa escola proporciona está problematizando essa relação entre trabalho, tecnologias e emancipação. Outra questão ainda se pode colocar: essa subjetividade que o trabalho flexível exige está funcionando a partir de que lógica, como adaptação ou autonomia? A essa segunda pergunta, é possível uma resposta como indicação do caminho que se pretende traçar.

Retomando o conceito de capital humano, a partir da visão de Foucault, percebe-se a construção de uma subjetividade para atender aos interesses econômicos. Para o autor, a subjetividade se refere às práticas por meio das quais o indivíduo constrói uma verdade sobre si. Em suas palavras, define subjetividade

\footnotetext{
2 A teoria crítica é uma expressão usada para caracterizar a tendência filosófica da Escola de Frankfurt, desenvolvida por Max Horkheimer. Nela, se configura a postura de identificar as contradições da realidade como imperfeições sociais e culturais, resultantes da racionalidade instrumental que está atrelada ao progresso capitalista. À razão instrumental, Horkheimer opõe a razão crítica.
}

Revista Educação Online, n. 16, mai-ago 2014, p. 23-40 
como: "a maneira pela qual o sujeito faz a experiência de si mesmo num jogo de verdade, no qual ele se relaciona consigo mesmo" (FOUCAULT apud REVEL, 2005, p. 85). A formação de competências, que são incorporadas como verdades sobre si, visa a formar indivíduos com capital humano para o mercado de trabalho.

Michel Foucault (2008) define capital humano como influência da ideologia neoliberal e como alvo de práticas educacionais, como

um capital humano no curso da vida dos indivíduos, que se colocam todos os problemas e que novos tipos de análise são apresentados pelos neoliberais. Formar capital humano, formar, portanto, essas espécies de competência-máquina que vão produzir renda, ou melhor, que vão ser remuneradas por renda, quer dizer o quê? Quer dizer, é claro, fazer o que se chama de investimentos educacionais. (p. 315)

Quanto melhor seu capital humano, maior a possibilidade de aumento da renda, mas também maior a possibilidade de desenvolvimento e crescimento para uma empresa, para o capitalismo. A busca pela permanente atualização do capital humano torna o indivíduo sujeitado aos interesses econômicos, ou seja, seduzido pelos seus estímulos, o indivíduo direciona sua vida para escolhas e desejos que ele não fez, que já foram estabelecidos por outros.

A busca pelo melhoramento do capital humano faz o pensar, sentir e agir de cada indivíduo ser direcionado para a construção de competências e habilidades, tornando-o um sujeito competitivo e fazendo com que as relações humanas se tornem comercializadas.

novas políticas gerenciais no campo da administração (management), práticas e saberes psicológicos voltados à dinâmica e à gestão de grupos e das organizações, propaganda, publicidade, marketing, branding, "literatura" de autoajuda etc. [...] induzindo os indivíduos a modificarem a percepção que têm de suas escolhas e atitudes referentes às suas próprias vidas e às de seus pares, de modo a que cada vez mais estabeleçam entre si relações de concorrência. (GADELHA, 2009, p. 151)

Esse cenário demonstra que estamos diante da construção de uma subjetividade submetida. Ideia também defendida por Viegas (2010, p. 186), o qual aponta que, ao mesmo tempo em que há uma liberação da subjetividade do trabalhador, há também uma submissão dessa aos objetivos da produtividade.

Retomando a relação educacional, Jean-Claude Forquin (1993, p. 20), ao tratar da educação na modernidade, defende que não podemos nos satisfazer com um discurso pedagógico instrumentalista, que faz a tarefa da educação ter como 
único alvo a formação de espíritos ágeis, adaptáveis, flexíveis para estarem preparados para as eventualidades.

Segundo Lukács (1969), nesta sociedade, cuja ênfase está no desenvolvimento das capacidades, tem-se, na verdade, uma alienação da personalidade humana, pois ela assume um caráter coercitivo em sua própria produção. Para superar essa coerção e buscar a autonomia, faz-se necessário designar o homem pelo trabalho como um ser que dá respostas. Pode-se ainda complementar, afirmando que o homem só responde porque há perguntas, problemas. A atividade de problematizar e o exercício de buscar respostas é para Lukács um trabalho. E nisso, a dimensão filosófica tem papel indispensável, como veremos a seguir.

Dessa maneira, retomemos a questão: como construir uma subjetividade emancipadora em meio a uma sociedade de consumo passivo de tecnologias e informação, para se adequar às necessidades do capital? A resposta pode estar na problematização da estrutura que sustenta a complexidade dessa realidade: a informação/conhecimento ${ }^{3}$.

Nessa sociedade tecnológica, em que se exige do trabalhador cada vez mais domínio dos mais variados conjuntos de informação, dificilmente está-se formando um sujeito capaz de questionar a produção do conhecimento, mas apenas um instrumento de reprodução do capital. "Nenhuma outra criação humana tornou-se instrumento mais valioso na atualidade do que o conhecimento capaz de fazer com que o capital se reproduza" (BAIBICH; MENEGHETTI, 2008, p. 90). Ainda, segundo Baibich e Meneghetti (2008, p. 93), tal como a postura da dialética negativa de Adorno, é preciso questionar os próprios pressupostos racionais que constroem a ciência.

Para essa compreensão, o saber filosófico é fundamental. Segundo Antonio J. Severino (2008, p. 166), pouco importa se terminando o ensino médio, o

\footnotetext{
${ }^{3}$ Neste trabalho, não utilizamos o termo informação e conhecimento como sinônimos. Entende-se a informação como conjunto de dados sobre algo, e o conhecimento como a capacidade de refletir e problematizar as informações dadas, tornando o indivíduo capaz da transformação do que está posto. Vivemos em uma época, em que a dependência da informação determina o fluxo da vida, das populações, das transações econômicas, decisões políticas, sistemas administrativos, Lei de Acesso à Informação etc. Contudo, não se pode afirmar, como alguns o fazem, que estamos em uma Sociedade do Conhecimento, isto porque, primeiro, não são todos os que têm acesso à informação, segundo, a capacidade de refletir criticamente sobre sua produção está ligeiramente reprimida.
}

Revista Educação Online, n. 16, mai-ago 2014, p. 23-40 
adolescente irá para a universidade ou para o mundo do trabalho; o que é essencial é uma formação filosófica que o leve a entender a construção histórica do conhecimento. "Isso quer dizer que não há processo de ensino, não há processo de aprendizagem, se não houver processo de produção, de construção do conhecimento" (SEVERINO, 2008, p. 166).

A questão do conhecimento, do trabalho e da tecnologia também é abordada por Hugo Assmann (2007). O autor afirma:

É óbvio que uma parte importante dos nossos conhecimentos formais deverá incluir a dimensão operacional, ou seja, ser conhecimento experimental e tecnicamente utilizável. Já neste terreno, a inventividade permanente requer um conhecimento flexível e criativo. Mas, do ponto de vista epistemológico, o problema não termina na flexibilização da operacionalidade técnica dos conhecimentos humanos. A questão epistemológica precisa incluir um novo modo de pensar o direcionamento do que pretendemos ser e fazer neste planeta. (p. 112)

Para Assmann (2007), no conhecimento socialmente significativo, estão associados dois elementos: a operacionalidade técnica e a dimensão ético-política. A técnica já está dada e se encontra em um contínuo processo de avanço sem limites. Por isso, se faz importante a dimensão da ética e da política, que precisam ser criadas no interior do processo de aprendizagem.

Já para Saviani (2007), o conhecimento deve ser o objeto do processo de ensino, pois compreender sua construção é indispensável para uma visão crítica do processo produtivo. "O papel fundamental da escola de nível médio será, então, o de recuperar essa relação entre o conhecimento e a prática do trabalho" (SAVIANI, 2007, p. 160).

Para tal empreendimento, entende-se como indispensável a postura teórica assumida por Gilles Deleuze e Félix Guattari (1992) na definição de filosofia. Para esses autores, a tarefa da filosofia é a de criar conceitos, atitude que só é possível pela problematização.

Todo o conceito remete a um problema, a problemas sem os quais não teria sentido, e que só podem ser isolados ou compreendidos na medida de sua solução [...]. Mas, mesmo na filosofia, não se cria conceitos, a não ser em função dos problemas que se considerem mal vistos ou mal colocados (pedagogia do conceito). (p. 27-28)

Em Deleuze e Guattari (1992), a criação de conceitos implica em uma atitude de criação de sentido, daquilo que é capaz de nos afetar, considerando-se que isso se realiza pela problematização. Os problemas são o ponto de partida para 
construção de sentido e de criação de conceitos. A verdadeira liberdade de pensamento está no movimento de problematização. Estar envolvido pelo problema é questão indispensável para construir sentido e conhecimento.

A ideia é defendida também por Silvio Gallo (2008), no texto Filosofia e o exercício do pensamento conceitual na educação básica. Para o autor, o problema é o "motor de arranque do pensamento", aquilo que força a pensar, coloca o pensamento em movimento. O problema produz novas conexões, criações, conceitos. "problema e conceito são as duas pontas da filosofia, de um pensamento não ortodoxo. [...] Problema suscita conceitos e conceito suscita problemas. Uns retornam sobre os outros produzindo novas experiências de pensamento" (GALLO, 2008, p. 70).

A atitude também está presente em Gonzalez Porta (2002), o problema "como modo filosófico de pensar". E na filosofia, como problematização do presente de Michel Foucault (2012), o qual afirma: “o pensamento é a liberdade em relação àquilo que se faz, o movimento pelo qual dele nos separamos, constituímo-lo como objeto e pensamo-lo como problema" (p. 225-226).

Pensar a filosofia a partir da articulação dos elementos conceito e problema, é fundamental para a problematização da atualidade, da relação informação versus conhecimento e reconhecer a filosofia como uma atividade política, no sentido de que a formação do aluno na educação tecnológica seja voltada para sua emancipação.

\section{Relato de pesquisa: o blog como instrumento pedagógico}

Tendo como base conceitual os teóricos já descritos, desenvolveu-se, durante o ano de 2013, o projeto de pesquisa "Educação, trabalho e tecnologias: do controle biopolítico à arte heterotópica", do qual participaram dois alunos bolsistas pelo Programa de Bolsas Acadêmicas de Inclusão Social - PBIS do Instituto Federal do Paraná.

Adotou-se como metodologia de pesquisa a investigação bibliográfica e a discussão entre os pesquisadores (professores e alunos/bolsistas), sendo o resultado publicado e discutido por meio da criação de um blog. Em um primeiro momento, os alunos bolsistas participaram das pesquisas e debates teóricos e, em 
seguida, desenvolveram a criação do blog e a produção do conteúdo a ser veiculado. O conteúdo postado foi desenvolvido a partir de temas que surgiram da pesquisa dos assuntos de interesse dos alunos do ensino técnico.

Como resultado, pode-se destacar que, além da compreensão teórica da temática, foram possíveis algumas realizações práticas: uma delas foi a criação do blog IF ETTec (http://ifettec.wordpress.com/), cujo acesso proporcionou maior e melhor produtividade por parte dos alunos, quando utilizado como recurso pedagógico em sala de aula.

Outra atividade realizada foi a criação de uma imagem que pudesse representar esse conjunto de conceitos em discussão (Figura 1). A obra foi denominada de "Aisthesis Tecnológica", a qual procura demonstrar que as tecnologias devem ser compreendidas como produto da criação humana e que, por isso, precisam ser utilizadas para a formação de um sujeito autônomo e para a criação de um mundo livre das desigualdades sociais.

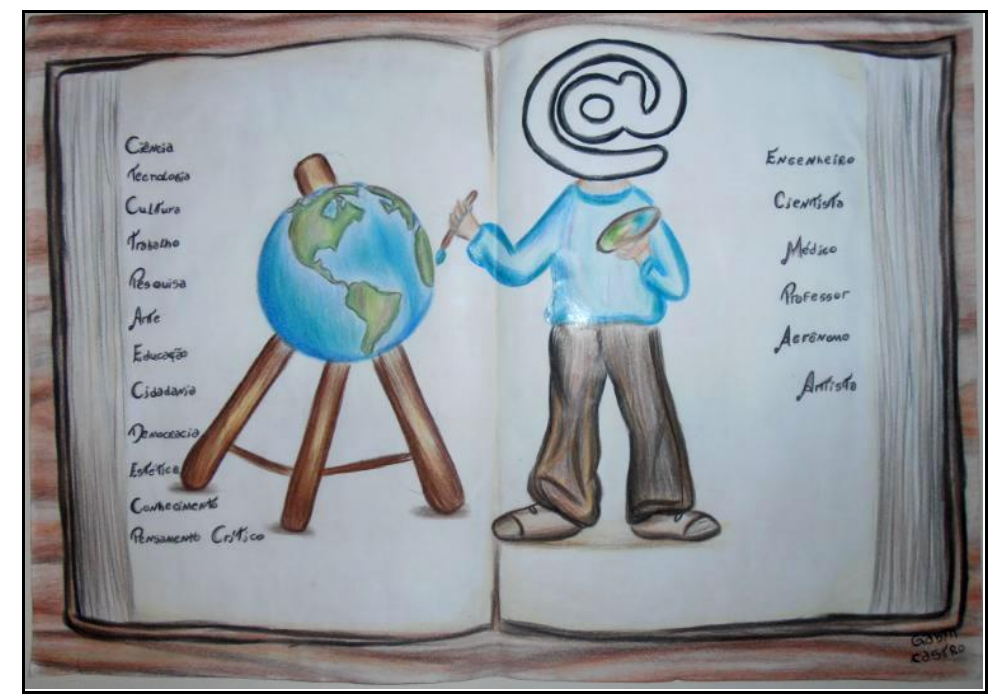

Figura 1: "Aisthesis Tecnológica" - representação que alude às tecnologias criadas pelo homem para a formação do próprio homem.

Autora da ilustração: Gabrieli C. Castro (aluna do 1ํ. ano de 2013 do curso Informática Integrado ao Ensino Médio no IFPR/Câmpus Assis Chateaubriand)

Com essa atividade pedagógica, buscou-se vivenciar o conceito de trabalho como princípio educativo, o que possibilitou ao educando tornar-se sujeito de sua própria história educacional, pois the permitiu apropriar-se da sua realidade, em uma interpretação que fosse capaz de promover a transformação das ideologias tecnológicas dominantes. Essa leitura é fundamental, nesta sociedade em que 
predomina uma interpretação das tecnologias guiada pela racionalidade instrumental, apontada nas críticas dos teóricos da Escola de Frankfurt e, como foi visto, nas ideias de Horkheimer.

Enfim, constatou-se a importância da disciplina de filosofia na educação tecnológica, como reflexão sobre o trabalho como princípio educativo, sendo esse conceito fundamental para a compreensão da constituição do sujeito (dimensão ontológica), como também o processo histórico de produção das ciências e das tecnologias. Dessa maneira, o projeto contribuiu para criar um espaço de discussão do papel da educação tecnológica e da formação do sujeito crítico e autônomo.

\section{Considerações Finais}

Este projeto proporcionou um espaço de discussão filosófica sobre a educação tecnológica emancipadora no Ensino Técnico do IFPR/Câmpus Assis Chateaubriand. O trabalho teórico se situou na compreensão da relação entre os conceitos de educação, trabalho e tecnologias, analisando o trabalho como princípio educativo (tanto do ponto de vista teórico quanto do ponto de vista da legislação) como condição para a leitura crítica dos conhecimentos científicos e tecnológicos. Nisso, o ensino da filosofia tem muito a contribuir, pois sua atitude crítica permite ao aluno problematizar sobre sua própria formação, construindo uma subjetividade autônoma. Com a expansão do ensino técnico de nível médio nos Institutos Federais de Educação Tecnológica, o desafio que se coloca a filosofia é proporcionar espaços de investigação do pensar e do fazer tecnológico.

\section{Referências Bibliográficas}

ARANHA, Maria Lúcia de Arruda. História da educação. São Paulo: Moderna. 1996.

ASSMANN, Hugo. Reencantar a educação: ruma à sociedade aprendente. 10ํㅡㄹ Petrópolis: Vozes, 2007.

BAIBICH, Tânia M. B; MENEGHETTI, Francis K. Ética, educação e formação na sociedade tecnológica: contribuições de Adorno, Horkheimer e Marcuse para a pedagogia do antipreconceito. In: SCHMIDT, M.A; GARCIA, T.M.F.B; HORN, G.B. (Orgs.). Diálogos e perspectivas de investigação. ljuí: Unijuí, 2008. p. 77-94.

CASTELLS, Manuel; CARDOSO, Gustavo (Orgs.). Sociedade em Rede: do conhecimento à acção política. Conferência promovida pelo Presidente da República. Centro Cultural de Belém: Imprensa Nacional-Casa da Moeda, 2006. 
DELEUZE, Gilles. Post-Scriptum sobre as sociedades de controle. In: Conversações: 1972-1990. Rio de Janeiro: Ed. 34, $1992 b$.

DELEUZE, Gilles; GUATTARI, Felix. O que é a filosofia? Rio de Janeiro: Ed. 34, 1992.

FORQUIN, Jean-Claude. Escola e cultura: as bases sociais e epistemológicas do conhecimento escolar. Porto Alegre: Artes Médicas, 1993.

FOUCAULT, Michel. Nascimento da biopolítica: curso dado no Collège de France (1978-1979). São Paulo: Martins Fontes, 2008.

2012.

Ética, sexualidade, política. 3aㅗ ed. Rio de Janeiro: Forense Universitária,

FRIGOTTO, Gaudêncio; CIAVATTA, Maria; RAMOS, Marise. O trabalho como princípio educativo no projeto de educação integral de trabalhadores - excertos. Disponível em: < http://juntosnaejadf.files.wordpress.com/2012/10/texto-completotrabalho princip educativo1.pdf>. Acesso em 30/08/2013.

GADELHA, Sylvio. Biopolítica, governamentalidade e educação: introdução e conexões, a partir de Michel Foucault. Belo Horizonte: Autêntica Editora, 2009.

GALLO, Silvio. Filosofia e o exercício do pensamento conceitual na educação básica. Revista Educação e Filosofia, v. 22, n. 44, p. 55-78, jul./dez. 2008.

GRAMSCI, Antonio. Cadernos do cárcere. Os Intelectuais. O princípio educativo. Jornalismo. 2ª̣ed. V2. Rio de Janeiro: Civilização Brasileira, 2001.

HORKHEIMER, Max. Eclipse da razão. São Paulo: Centauro, 2002.

LUKÁCS, Georg. As bases ontológicas do pensamento e da atividade do homem. 1969. Disponível em: <http://www.giovannialves.org/Bases Luk\%E1cs.pdf>. Acesso em 2/9/2013.

MARX, Karl. O método da economia política. In: Para uma crítica da economia política. Edição eletrônica de Ridendo C. Mores, 1999, p. 37-55.

MINISTÉRIO DA EDUCAÇÃO. Diretrizes Curriculares Nacionais para a Educação Profissional Técnica de Nível Médio. Parecer CNE/CEB № 11/2012. Disponível em: <http://portal.mec.gov.br/index.php?option=com_content\&id=12992:diretrizes-para-aeducacao-basica>. Acesso em 23/07/2013.

. Diretrizes Curriculares Nacionais para o Ensino Médio. Parecer CNE/CEB №: 5/2011. Disponível em: <http://portal.mec.gov.br/index.php?option=com_content\&id=12992:diretrizes-para-aeducacao-basica>. Acesso em 19/06/2013.

. Parâmetros Curriculares Nacionais: Ensino Médio. Brasília: MEC, 2000.

. Resolução no 2, de 30 de janeiro de 2012. Disponível em:

<http://portal.mec.gov.br/index.php?option=com_content\&id=12992:diretrizes-para-aeducacao-basica>. Acesso em 19/06/2013.

Resolução $n^{\circ}$ 6, de 20 de setembro de 2012. Disponível em: $<$ http://portal.mec.gov.br/index.php?option=com_content\&id=12992:diretrizes-para-aeducacao-basica>. Acesso em 23/07/2013. 
PRESIDÊNCIA DA REPÚBLICA. Lei no 9.394, de 20 de dezembro de 1996. Disponível em: <http:/www.planalto.gov.br/ccivil_03/Leis/L9394.htm>. Acesso em 04/04/2013.

. Lei no 11.741, de 16 de julho de 2008. Disponível em: < http://www.planalto.gov.br/ccivil_03/_Ato2007-2010/2008/Lei/L11741.htm>. Acesso em 23/07/2013.

PINTO, Álvaro V. Sete lições sobre a educação de adultos. São Paulo: Cortez, 2003. PORTA, Mario Ariel González. A filosofia a partir de seus problemas. São Paulo: Editora Loyola, 2002.

RAMOS, Marise N. O projeto unitário de ensino médio sob os princípios do trabalho, da ciência e da Cultura. In: FRIGOTTO, Gaudêncio; CIAVATTA, Maria. Ensino médio: ciência, cultura e trabalho. Brasília: MEC/SETEC, 2004. p. 37-52.

REVEL. Judith. Michel Foucault. conceitos essenciais. São Carlos: Claraluz, 2005.

SAVIANI, Dermeval. O trabalho como princípio educativo frente as novas tecnologias. Disponível em:

<http://forumeja.org.br/go/files/demerval\%20saviani.pdf>. Acesso em 30/08/2013. . Trabalho e educação: fundamentos ontológicos e históricos. Revista Brasileira de Educação, v. 12, n. 34, p. 152-180, jan./abr. 2007.

SEVERINO, Antônio J. A filosofia na formação do adolescente no Ensino Médio. In: SCHMIDT, M.A; GARCIA, T.M.F.B; HORN, G.B. (Orgs.). Diálogos e perspectivas de investigação. ljuí: Unijuí, 2008. p. 165-178.

VIEGAS, Moacir. Teoria crítica e formação do trabalhador flexível: contradições e possibilidades de emancipação. In: PEREIRA, Marcelo de A. (Org.). Filosofia e educação: articulações, confrontos e controvérsias. Pelotas: Ed. da UFPEL, 2010. p.173-193. 